\title{
Evaluation of a New Force Field for Describing the Adsorption Behavior of Alkanes in Various Pure Silica Zeolites
}

\author{
Bei Liu, ${ }^{* * *}$ Berend Smit, ${ }^{\dagger, *}$ and Sofia Calero ${ }^{\S}$ \\ Centre Européen de Calcul Atomique et Moléculaire (CECAM), Ecole Normale Supérieure, 46 allée d'Italie, \\ 69007 Lyon, France, Van't Hoff Institute for Molecular Sciences, University of Amsterdam, Nieuwe \\ Achtergracht 166, 1018 WV Amsterdam, The Netherlands, and Department of Physical, Chemical, and Natural \\ Systems, University Pablo de Olavide, Ctra. Utrera km. 1.41013, Seville, Spain
}

Received: July 13, 2006; In Final Form: August 3, 2006

\begin{abstract}
The recently proposed united atom force field by Dubbeldam et al. (Phys. Rev. Lett. 2004, 93, 088302) for the adsorption of alkanes in MFI-type zeolites was extended to other zeolites in this work. Its applicability to FER-type zeolites was evaluated in detail, for which the Henry coefficients, the isosteric heat of adsorption, the adsorption isotherms, as well as the locations of alkanes in the FER-type zeolites were computed and compared to experimental values. The results show that the new force field works well for FER zeolites. Furthermore, its applicability to MWW-, MTW-, CFI-, LTA-, and STF-type zeolites was investigated, and we found that the experimental isotherms could be accurately predicted except for STF-type zeolites. This work shows that the new united atom force field proposed by Dubbeldam et al. is applicable to most pure silica zeolites.
\end{abstract}

\section{Introduction}

Zeolites are microporous materials that have found wide applications as efficient heterogeneous catalysts and adsorbents in the petrochemical industry, for which the adsorption of hydrocarbons in zeolite pores plays an important role. Therefore, it is of great importance to explore the adsorption behavior of hydrocarbons in different zeolites from both scientific and practical points of view. In addition to experiment, molecular simulation has been proved a useful tool to investigate the properties of fluids confined in porous materials. ${ }^{1}$ It not only provides a cost-effective way of determining adsorption isotherms, especially under conditions not readily amenable to experiments, but also gives molecular-level details of the microstructure of the confined fluids, such as the molecular conformation and adsorption location to enable one to examine the underlying physics that may be inaccessible by experiments.

It is commonly recognized that reliable force fields for the interatomic potentials play a key role in molecular simulations. ${ }^{2}$ As a result, many force fields ${ }^{3-7}$ have been proposed for the interactions between the adsorbates and the zeolite framework and for the adsorbate-adsorbate interactions. Most force fields are zeolite-dependent, and a general force field applicable to most zeolites is of great usefulness. Recently, Dubbeldam et al. ${ }^{8,9}$ developed a united atom (UA) force field, able to accurately and quantitatively describe the adsorption properties of alkanes in nanoporous framework structures. This force field faithfully reproduces the experimentally determined isotherms (particularly the inflection points) in pure silica MFI-type zeolites and has been successfully extended to TON-, AFI-, DDR-, and MWWtype zeolites. It seems that this force field is promising to become a general force field applicable to most types of pure

\footnotetext{
* Corresponding author. E-mail: bliu@ science.uva.nl.

$\dagger$ CECAM.

$\doteqdot$ University of Amsterdam.

$\S$ University Pablo de Olavide.
}

silica zeolites, and thus in this work we test its applicability to other pure silica zeolites not considered previously to come to a conclusion.

The aim of this work is two-fold. The first is to check whether united atom force fields work for FER-type zeolites, for which we evaluate the recently proposed force field by Dubbeldam et al. against experimental data and existing simulations using other force fields whenever possible. The reason FER is chosen is that the $n$-alkane-FER systems, in which the adsorbate molecules fit tightly in the zeolite pores, provide a very demanding test case for the simulation force fields. ${ }^{10-12}$ Pascual et al. ${ }^{13,14}$ pointed out that the united atom force fields are questionable for describing the adsorption of alkanes in FERtype zeolites and attributed this to the simple approximations in the UA force field. The more complex anisotropic united atom (AUA) potential scheme was used in their work. Therefore, it is worth performing a systematic study for the $n$-alkaneFER system by using the new UA force field. The second aim is to check the applicability of this force field to other pure silica zeolites to evaluate whether it can serve as a general force field for most structures.

\section{Simulation Models and Methods}

2.1. Zeolite Models. In the simulations, zeolites were constructed by using the atomic coordinates reported, ${ }^{15-20}$ and some details of these structures are summarized in Table 1. The zeolite lattices were assumed to be rigid in the simulations, because the flexibility of the framework has a negligible influence on the adsorption of alkanes. ${ }^{22}$

2.2. Force Field. The force field used in this work is the united atom force field proposed by Dubbeldam et al. ${ }^{8,9}$ The alkanes are described with a united atom model, in which $\mathrm{CH}_{3}$ and $\mathrm{CH}_{2}$ groups are considered as single interaction centers. ${ }^{23}$ The beads in the chain are connected by harmonic bonding potentials. A harmonic cosine bending potential models the bond bending between three neighboring beads, and a Ryckaert- 
TABLE 1: Structural Information for the Pure Silica Zeolites Considered in This Work

\begin{tabular}{|c|c|c|c|c|c|c|}
\hline \multirow[b]{2}{*}{ zeolite } & \multirow{2}{*}{$\begin{array}{l}\text { IZA } \\
\operatorname{code}^{21} \\
\end{array}$} & \multirow{2}{*}{$\begin{array}{l}\text { structure, } \\
\text { pore dimension }(\AA)\end{array}$} & \multirow[b]{2}{*}{ unit cell $(\AA)$} & \multicolumn{3}{|c|}{ simulation cell size $(\AA)$} \\
\hline & & & & $x$ & $y$ & $z$ \\
\hline ferrierite & FER & $\begin{array}{l}10,5.4 \times 4.2 \\
8,4.8 \times 3.5\end{array}$ & $a=19.156, b=14.127, c=7.489$ & 38.312 & 28.254 & 29.956 \\
\hline ZSM-12 & MTW & $12,6.0 \times 5.6$ & $a=24.863, b=5.012, c=24.326$ & 49.726 & 40.096 & 48.652 \\
\hline ITQ-1 & MWW & $\begin{array}{l}10,7.1 \times 18.0 \\
10,4.0 \times 5.5\end{array}$ & $a=24.447, b=14.114, c=24.882$ & 24.447 & 28.228 & 24.882 \\
\hline CIT-5 & CFI & $14,7.3 \times 7.55$ & $a=13.695, b=5.021, c=25.497$ & 41.085 & 30.126 & 50.994 \\
\hline ITQ-29 & LTA & supercages, 11.8 & $a=11.867$ & 47.468 & 47.468 & 47.468 \\
\hline SSZ-35 & STF & $\begin{array}{l}10,5.5 \times 6.1 \\
18,12.5 \times 9\end{array}$ & $a=11.411, b=11.526, c=7.377$ & 34.233 & 34.578 & 36.885 \\
\hline
\end{tabular}

TABLE 2: Henry Coefficients $K_{\mathrm{H}}[\mathrm{mmol} / \mathrm{g} / \mathrm{Pa}]$ and Isosteric Heats of Adsorption at Infinite Dilution $Q_{\mathrm{st}}{ }^{0}[\mathrm{~kJ} / \mathrm{mol}]$ of $\mathrm{C}_{1-} \mathrm{C}_{3}$ in FER-type Zeolites

\begin{tabular}{|c|c|c|c|c|c|c|}
\hline & \multicolumn{2}{|c|}{$\mathrm{CH}_{4}$} & \multicolumn{2}{|c|}{$\mathrm{C}_{2} \mathrm{H}_{6}$} & \multicolumn{2}{|c|}{$\mathrm{C}_{3} \mathrm{H}_{8}$} \\
\hline & $K_{\mathrm{H}}$ & $Q_{\mathrm{st}}{ }^{0}$ & $K_{\mathrm{H}}$ & $Q_{\mathrm{st}}{ }^{0}$ & $K_{\mathrm{H}}$ & $Q_{\mathrm{st}}{ }^{0}$ \\
\hline experimental data ${ }^{26}$ & $2.0 \times 10^{-5}$ & 27.7 & $7.2 \times 10^{-4}$ & 41.7 & & 53.3 \\
\hline this work & $9.38 \times 10^{-6}$ & 21.43 & $2.3 \times 10^{-4}$ & 33.43 & $1.51 \times 10^{-3}$ & 44.27 \\
\hline $\begin{array}{l}\text { Ndjaka et al. } \\
\quad(\text { simulation data })^{28}\end{array}$ & $7.2 \times 10^{-6}$ & 21.6 & $1.9 \times 10^{-4}$ & 34.2 & $9.1 \times 10^{-4}$ & 43.9 \\
\hline
\end{tabular}

Bellemans potential controls the torsional angle. The interactions between the adsorbates as well as the adsorbates and the zeolite are described by Lennard-Jones potentials. For a detailed description of the force field, the reader is referred to ref 9.

2.3. Simulation Technique. For the calculation of the Henry coefficients and the isosteric heats of adsorption at infinite dilution $Q_{\text {st }}{ }^{0}$, we performed configurational-bias Monte Carlo (CBMC) simulations in the NVT ensemble. Each simulation consists of at least $4 \times 10^{7}$ cycles, and in each cycle one move is chosen at random with a fixed probability 0.1 for a molecule translation, 0.1 for rotation around the center of mass, and 0.8 for regrowth of the entire molecule. During the simulation, we compute the Rosenbluth factor and the internal energy $\Delta U$, which are directly related to the Henry coefficient and $Q_{\mathrm{st}}{ }^{0}$, respectively. ${ }^{24,25}$

Adsorption isotherms were calculated in the grand-canonical ensemble using the CBMC method. The CB-GCMC method simulates an open system specified by fixed temperature $T$, volume $V$, and fugacity $f$. We converted the imposed fugacity to the corresponding pressure using the Peng-Robinson equation of state. Four types of moves were carried out: translation, rotation, exchange of molecules between the zeolite and a molecule reservoir, and partial regrowths. All simulations included at least $2 \times 10^{7}$ cycles.

The statistical uncertainty was estimated by dividing each run into five blocks and calculating the standard deviation from the block averages. The standard deviation is within $\pm 10 \%$ for every simulation. A detailed description of the simulation methods can be found in our previous work. ${ }^{9}$

\section{Results and Discussion}

3.1. Validation of the Applicability of the New Force Field to Ferrierite (FER Topology) Zeolites. As a first step toward validation of the applicability of the force field proposed by Dubbeldam et al. to ferrierite zeolites, the Henry coefficients of $\mathrm{C}_{1-} \mathrm{C}_{3}$ and the isosteric heat of adsorption $Q_{\mathrm{st}}{ }^{0}$ of $\mathrm{C}_{1-} \mathrm{C}_{6}$ were calculated and compared to experimental ${ }^{26,27}$ and simulation ${ }^{14,28}$ results, as shown in Table 2 and Figure 1. The force field shows results improved on or comparable to those of previous simulations, and the agreement with the experimental values is also satisfactory considering the fact that the experiments have been performed in the protonated ferrierite samples. It has been shown that the presence of the protons can give a negative

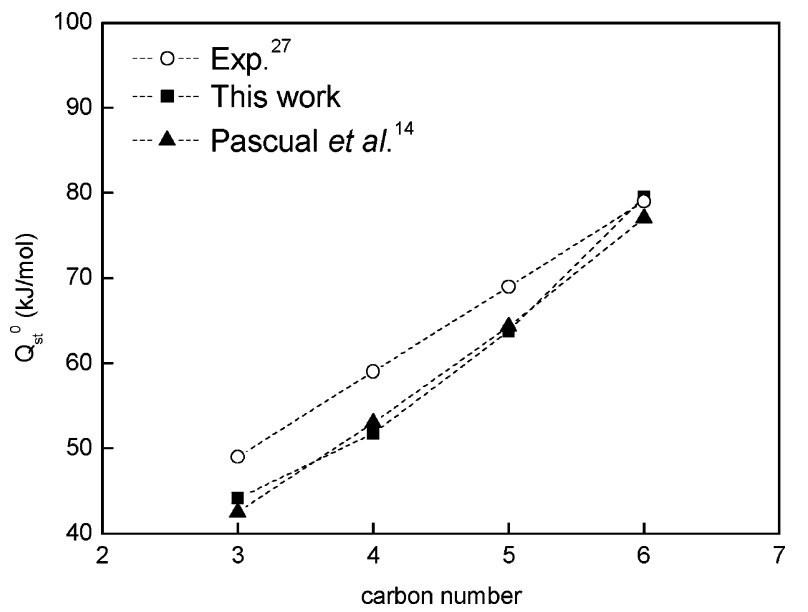

Figure 1. Heats of adsorption of linear alkanes in FER as a function of the carbon number, as compared to experiments and previous simulations.

contribution to the heat of adsorption of up to $10 \mathrm{~kJ} / \mathrm{mol}$ for H-MFI and H-MOR. ${ }^{29,30}$

To test the applicability of the force field further, the adsorption isotherms of $\mathrm{C}_{1-} \mathrm{C}_{6}$ were computed and compared to experimental data ${ }^{11,26,27}$ and previous simulation results, ${ }^{12-14}$ as shown in Figure $2 \mathrm{a}-\mathrm{f}$. It should be pointed out that all of the adsorption isotherms were measured in the protonated ferrierite samples, and no measurements in pure silica ferrierite samples have been performed.

Figure 2a gives the computed adsorption isotherms of methane and ethane at $309 \mathrm{~K}$. Our simulations show lower values than the experimental observations, and similar deviation has been observed by other simulations using a different force field. ${ }^{28}$ The computed isotherms for propane at $333 \mathrm{~K}$ are shown in Figure 2b, and a good agreement with Pascual et al.'s simulation results is obtained for the one in pure silica FER. In the case of $n$-butane, the isotherm in pure silica structure agrees well with the simulation results of van Santen et al., ${ }^{12}$ while they give lower values than both the experimental and the simulation results of Pascual et al. ${ }^{13}$ The adsorption isotherms for $n$-pentane at 333 and $298 \mathrm{~K}$ are shown in Figure $2 \mathrm{~d}$ and e, respectively. We found that our UA force field faithfully reproduces the experimental type-I isotherms, while a huge step was observed on van Santen et al.'s simulation results. Figure 

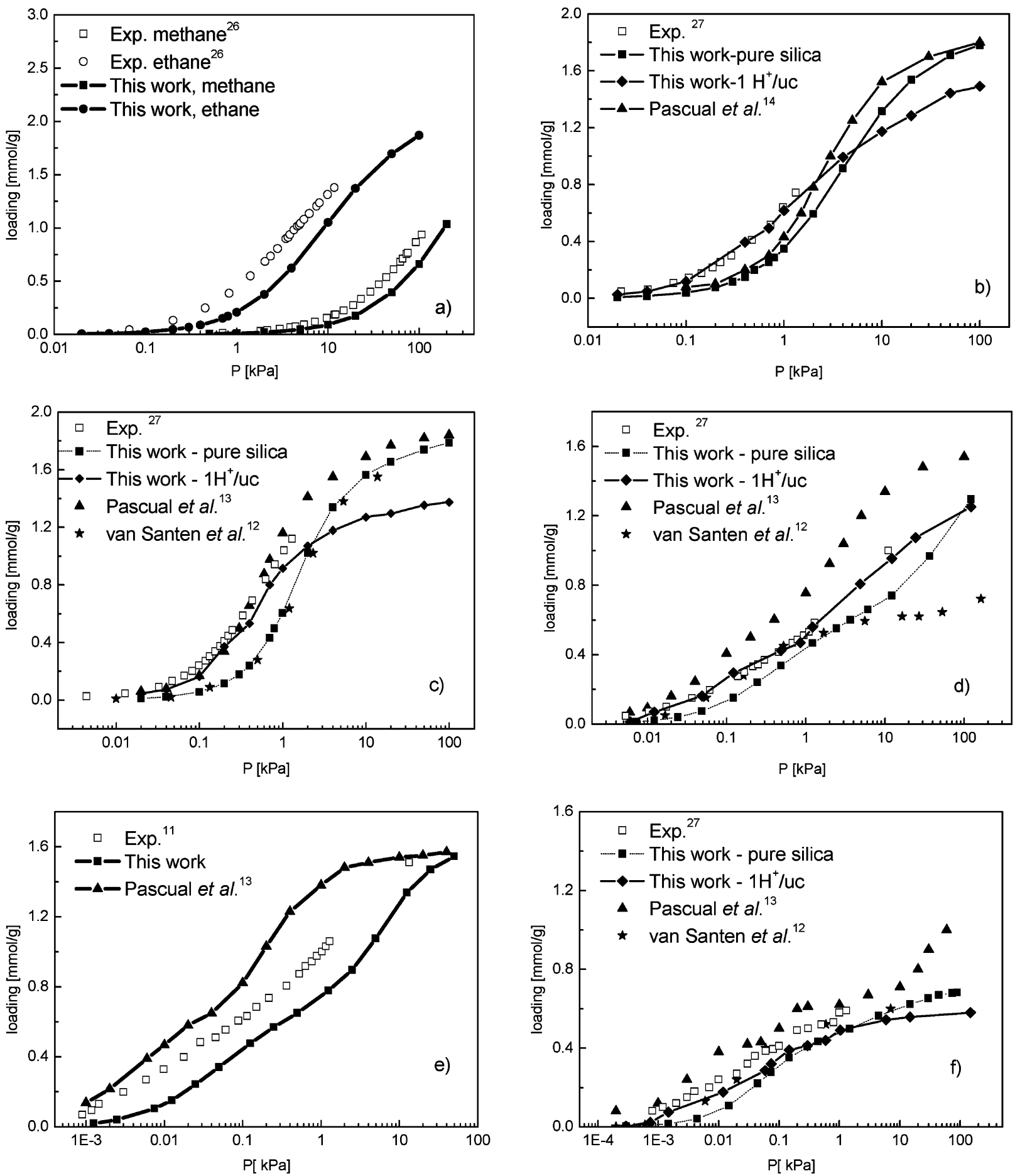

Figure 2. Comparison of the experimental and simulated adsorption isotherms of (a) methane and ethane, (b) propane, (c) $n$-butane, (d) $n$-pentane$333 \mathrm{~K}$, (e) $n$-pentane- $298 \mathrm{~K}$, and (f) $n$-hexane in ferrierite zeolite at various temperatures.

$2 \mathrm{f}$ gives the adsorption isotherms for $n$-hexane at $333 \mathrm{~K}$. A difference in the shape of the simulated adsorption isotherms was found. Pascual et al. predicted that hexane molecules could adsorb in the 8-ring cages when the pressure is higher than 10 $\mathrm{kPa}$, and this unusual behavior has not been confirmed by experiments. In contrast, our simulation shows that before the bulk saturation pressure is reached, hexane molecules can only adsorb in the 10-ring channels, as shown in Figure 3, which is consistent with the experimental observations. ${ }^{11,31-33}$

From Figure $2 \mathrm{a}-\mathrm{f}$ we can see our simulations based on the new UA force field show systematic lower adsorption capacities in pure silica FER-type zeolite than the experimental values for all of the alkanes tested, which can be attributed to the presence of protons in the experimental zeolite samples. To test this hypothesis, we performed some simulations using the force field of Calero et al., ${ }^{30}$ an extended version of the force field of Dubbeldam et al. that takes into account the effects of protons, for alkanes in protonated zeolites, as shown in Figure $2 b-d$,f. For Figure 2a and e, the experiments are on zeolites with a different $\mathrm{Si} / \mathrm{Al}$ ratio as compared to the other isotherms in FER. For these zeolites, the proton distribution is much more complex; because there are four distinct T-sites, aluminum can be located, and the positions and stability of protons in the zeolites are strongly related to its $\mathrm{Al}$ distribution. Our simulations show that the adsorption properties are very sensitive to the exact location of $\mathrm{Al} ;{ }^{34}$ however, in this work only the structure that gives the 
TABLE 3: Henry Coefficients $K_{\mathrm{H}}$ and Isosteric Heats of Adsorption at Infinite Dilution $Q_{\mathrm{st}}{ }^{0}$ of $\mathrm{C}_{1-} \mathrm{C}_{3}$ in $\mathrm{MTW}$-type Zeolites

\begin{tabular}{|c|c|c|c|c|c|c|}
\hline & \multicolumn{2}{|c|}{$\mathrm{CH}_{4}$} & \multicolumn{2}{|c|}{$\mathrm{C}_{2} \mathrm{H}_{6}$} & \multicolumn{2}{|c|}{$\mathrm{C}_{3} \mathrm{H}_{8}$} \\
\hline & this work & exp. ${ }^{26}$ & this work & exp..$^{26}$ & this work & $\exp .^{26}$ \\
\hline$K_{\mathrm{H}}[\mathrm{mmol} / \mathrm{g} / \mathrm{Pa}]$ & $3.6 \times 10^{-6}$ & $4.0 \times 10^{-6}$ & $6.9 \times 10^{-5}$ & $9.3 \times 10^{-5}$ & $4.0 \times 10^{-6}$ & \\
\hline$Q_{\mathrm{st}}{ }^{0}[\mathrm{~kJ} / \mathrm{mol}]$ & 18.5 & 20.9 & 28.1 & 29.5 & 37.5 & 37.6 \\
\hline
\end{tabular}

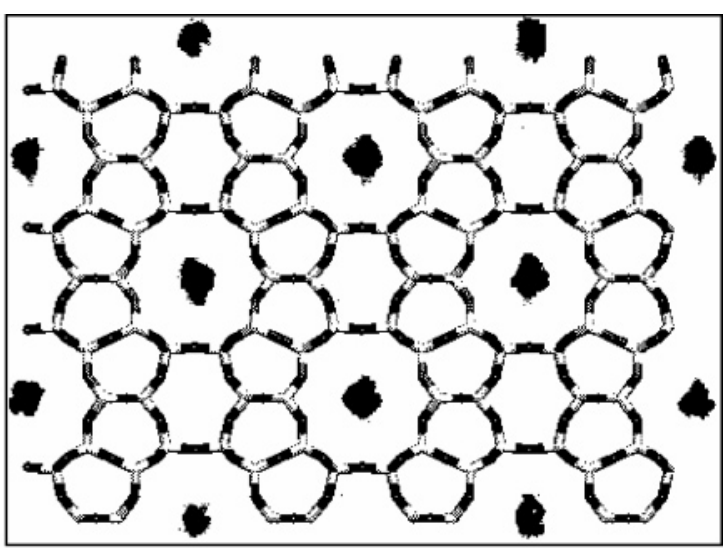<smiles>[X]C(C)I</smiles>

Figure 3. Distribution of hexane in FER zeolites at $74 \mathrm{kPa}$ and 333 $\mathrm{K}$. The centers of mass of the hexane molecules are represented by black dots.

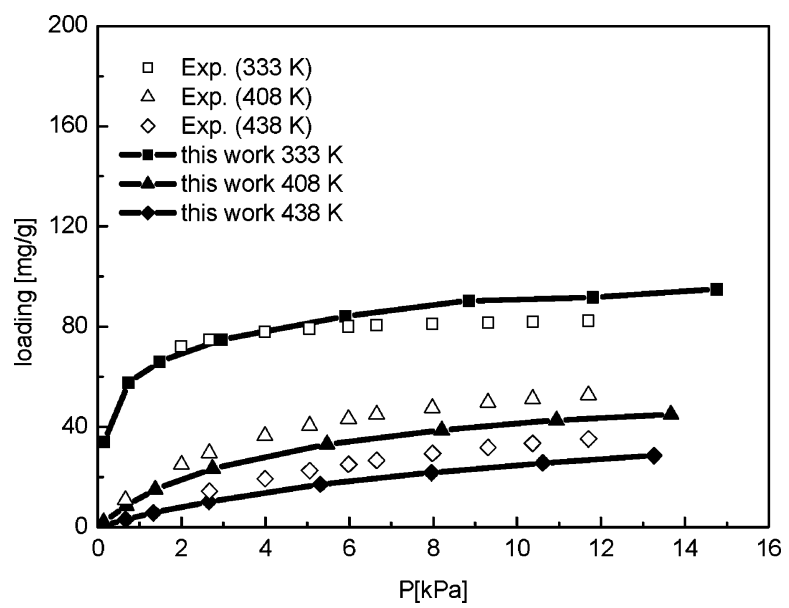

Figure 4. Comparison of the experimental ${ }^{35}$ and simulated adsorption isotherms of $n$-hexane in ITQ-1 zeolite.

best agreement with the experimental data is presented. Figure 2 shows that indeed this shift could be explained by the presence of protons. We could also have shown results for different $\mathrm{Al}$ distributions that are less successful, which makes it very difficult to conclude that protons are the only explanation. However, these results do show that the disagreement with the experimental data does not necessarily imply the difficulties of the force field of Dubbeldam et al. On the other hand, the simulated results of Pascual et al. show that the presence of protons can increase the adsorption capacity of propane, the effects are negligible for $n$-butane, and it decreases the adsorption capacity of $n$-pentane and $n$-hexane. However, from the physical point of view one would expect that protons would affect the adsorption of alkanes in a similar way. Therefore, our simulations using the new force field give more reasonable results as compared to those of Pascual et al. These results together with those of Henry coefficients and heats of adsorption show that the UA force field of Dubbeldam et al. is applicable
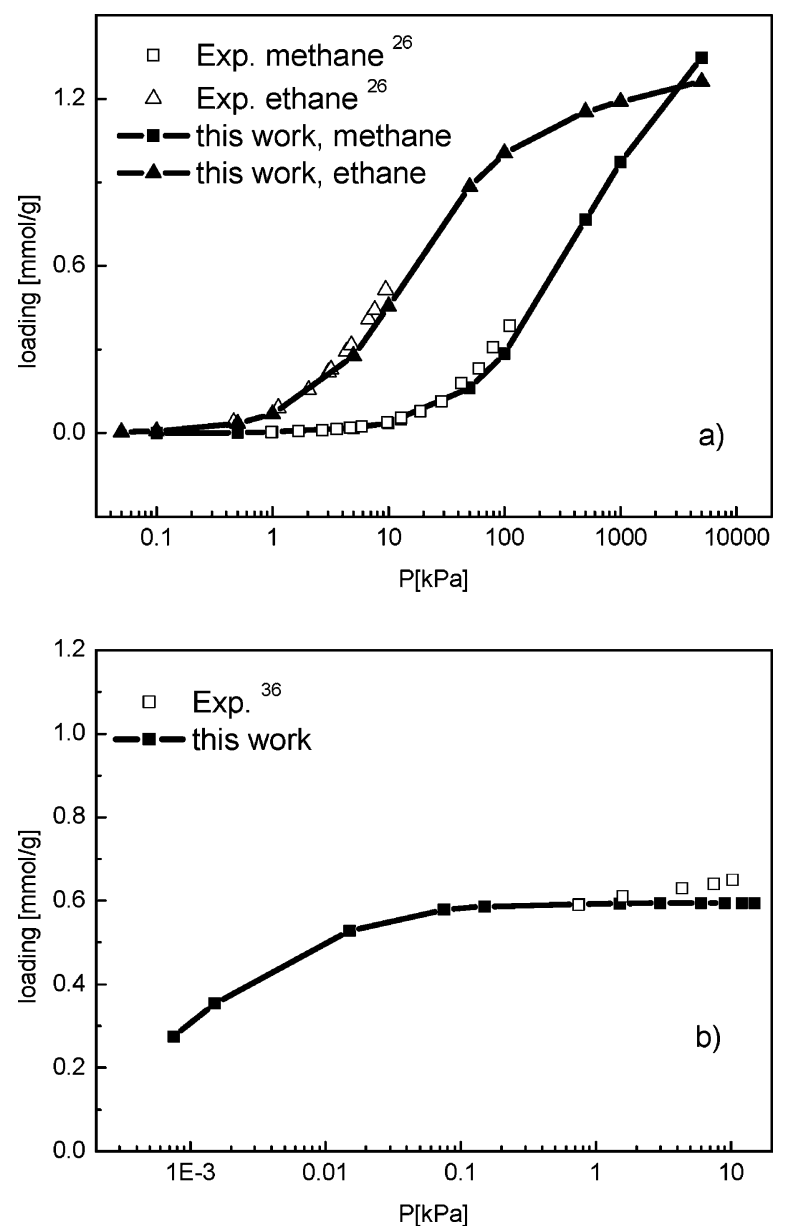

Figure 5. Comparison of the experimental and simulated adsorption isotherms of (a) methane and ethane and (b) n-hexane in ZSM-12 zeolite.

TABLE 4: Heats of Hexane Adsorption in Four Zeolites

\begin{tabular}{lccc}
\hline \multicolumn{1}{c}{ zeolite } & this work & exp. $^{37}$ & calc. $^{37}$ \\
\hline ZSM-12 (MTW) & $71.98 \pm 0.63$ & 72 & $64.2 \pm 2.5$ \\
CIT-5 (CFI) & $51.90 \pm 0.20$ & 46 & $55.6 \pm 0.4$ \\
ITQ-29 (LTA) & $46.62 \pm 0.40$ & 39 & 46.6 \\
SSZ-35 (STF) & $52.04 \pm 0.17$ & 57 & $54.4 \pm 2.6$
\end{tabular}

to the characterization of FER-type zeolites. Unlike the statement of Pascual et al. ${ }^{13,14}$ that the UA force fields are questionable for describing the adsorption of alkanes in FER-type zeolites, this work shows that UA force fields are workable for this kind of system.

3.2. Validation of the Applicability of the New Force Field to Other Pure Silica Zeolites. In addition to the ferrierite zeolites, the applicability of this force field to ITQ-1 (MWW), ZSM-12 (MTW), CIT-5 (CFI), ITQ-29 (LTA), and SSZ-35 (STF) zeolites was further examined in this work. The results of the simulations at infinite dilution are given in Tables 3 and 4 , and the results for the adsorption isotherms are shown in Figures 4-6. In both cases, the results are compared to the experiments of Savitz et al., ${ }^{26} \mathrm{Du}$ et al., ${ }^{35}$ Guil et al., ${ }^{36}$ and Gribov et al. ${ }^{37}$ It should be pointed out that all of the experimental data used were measured in pure silica samples. 

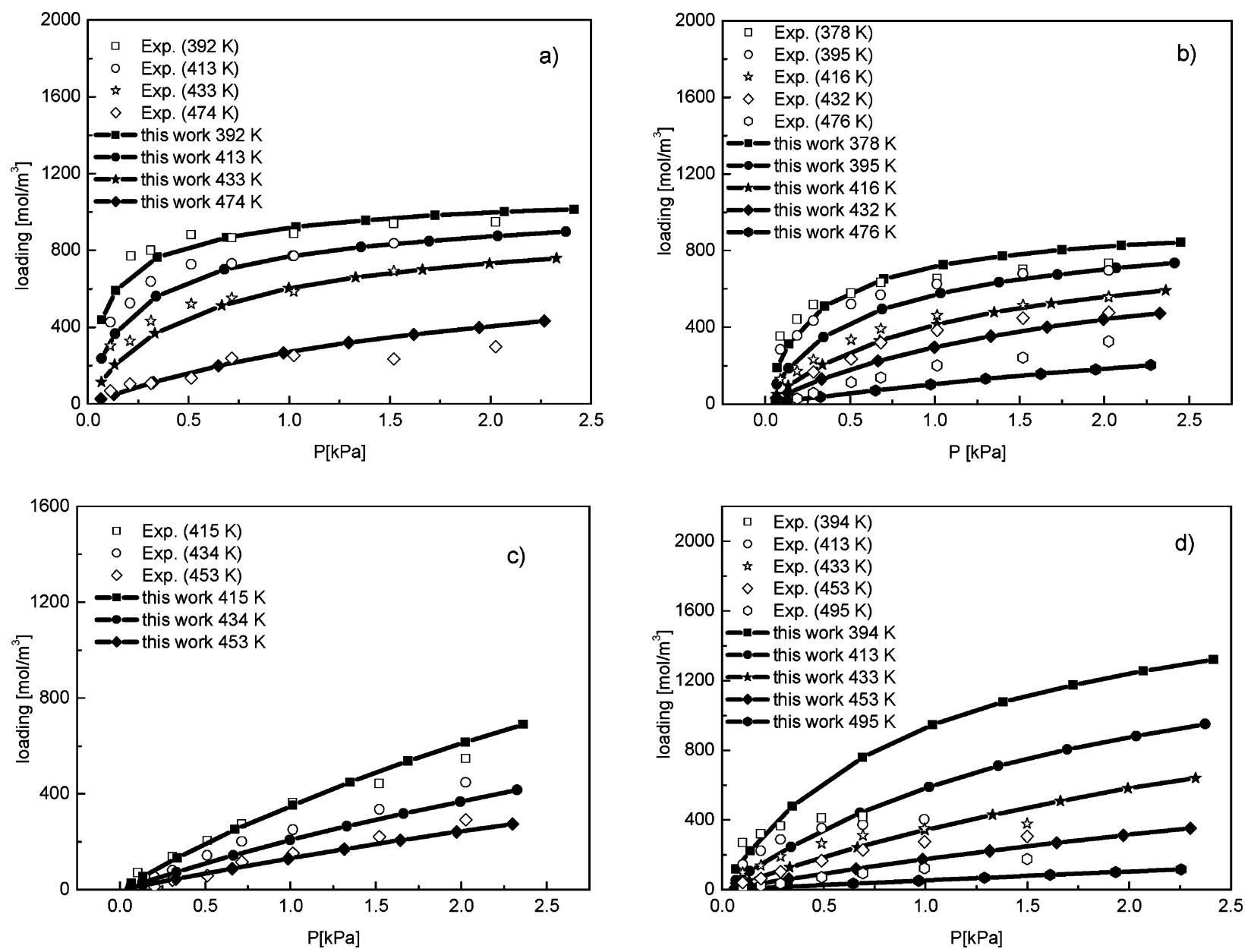

Figure 6. Comparison of the experimental ${ }^{37}$ and simulated adsorption isotherms of $n$-hexane in four silica zeolites: (a) ZSM-12, (b) CIT-5, (c) ITQ-29, and (d) SSZ-35.

Figure 4 shows our simulation results for hexane at various temperatures as compared to the experimental data of $\mathrm{Du}$ et al. ${ }^{35}$ for zeolite ITQ-1, and a good agreement was obtained. Savitz et al. ${ }^{26}$ measured adsorption data for methane, ethane, and propane in ZSM-12 zeolite. Our simulations are in excellent agreement with their experimental values (Table 3 and Figure $5 a)$. In addition to small alkanes, $n$-hexane was also considered, and the simulation results at $315 \mathrm{~K}$ are shown in Figure $5 \mathrm{~b}$, in which the experimental data of Guil et al. ${ }^{36}$ are also given for comparison. Again, the agreement is good. It is shown that the force field can be successfully extended from MFI-type to MWW- and MTW-type zeolites.

Recently, Corma et al. ${ }^{37}$ carried out a systematic theoretical and experimental study on the adsorption of $n$-hexane on a series of pure silica zeolites. The heat of adsorption of $n$-hexane on different zeolites was investigated in detail, and for ZSM-12, CIT-5, ITQ-29, and SSZ-35 zeolites the adsorption isotherms were also measured at various temperatures. A detailed comparison with their results was carried out in this work. Table 4 shows the computed heat of adsorption, as compared to their experimental and calculation results. Our values are in agreement with their results. The comparisons between our computed isotherms and their results are given in Figure 6. Because the unit of loading is absorbance (au) in the experimental work, a conversion factor is needed to translate their IR data into quantitative values. Figure 6 shows that the experimental isotherms could be accurately predicted except for STF-type zeolites. The discrepancy between simulations and experiments for STF-type zeolites may be attributed to the reasons that perfect structures are used in the simulations, while the experimental samples may be not completely accessible due to intergrowths and partial blocking of the pores.

\section{Conclusions}

The simulation results presented in this work show that the UA force field of Dubbeldam et al. developed for MFI-type zeolites is applicable to other pure silica zeolites, such as FER-, MWW-, MTW-, CFI-, and LTA-type zeolites. It may be concluded that this UA force field is a general force field applicable to most pure silica zeolites that may find wide applications in the petrochemical industry.

Acknowledgment. B.L. and B.S. gratefully acknowledge the financial support from the Dutch STW/CW program Separation Technology (700.56.655-DPC.6243) and the EC Marie Curie EXT project MEXT-CT-2005-023311. S.C. acknowledges the support of the Spanish "Ministerio de Educación y Ciencia" for Ramón y Cajal Program and the projects CTQ2004-00582/ BQU, CTQ2004-07730-C02-01/BQU, and VEM2003 20574 C03 01. We wish to thank G. Sastre, F. Rey, and T. L. M. Maesen for useful discussions.

\section{References and Notes}

(1) Catlow, C. R. A.; van Santen, R. A.; Smit, B. Computer Modelling of Microporous Materials; Elsevier Science: Amsterdam, 2004.

(2) Krishna, R.; Smit, B.; Calero, S. Chem. Soc. Rev. 2002, 31, 185.

(3) June, R. L.; Bell, A. T.; Theodorou, D. N. J. Phys. Chem. 1992 96, 1051. 
(4) Smit, B.; Loyens, L. D. J. C.; Verbist, G. L. M. M. Faraday Discuss. 1997, 106, 93. 7183.

(5) Maris, T.; Vlugt, T. J. H.; Smit, B. J. Phys. Chem. B 1998, 102,

(6) Vlugt, T. J. H.; Krishna, R.; Smit, B. J. Phys. Chem. B 1999, 103, 1102.

(7) Pascual, P.; Ungerer, P.; Tavitian, B.; Pernot, P.; Boutin, A. Phys. Chem. Chem. Phys. 2003, 5, 3684.

(8) Dubbeldam, D.; Calero, S.; Vlugt, T. J. H.; Krishna, R.; Maesen,

T. L. M.; Beerdsen, E.; Smit, B. Phys. Rev. Lett. 2004, 93, 088302.

(9) Dubbeldam, D.; Calero, S.; Vlugt, T. J. H.; Krishna, R.; Maesen,

T. L. M.; Smit, B. J. Phys. Chem. B 2004, 108, 12301.

(10) van Well, W. J. M.; Cottin, X.; de Haan, J. W.; van Santen, R. A.; Smit, B. Angew. Chem., Int. Ed. 1998, 37, 1081.

(11) van Well, W. J. M.; Cottin, X.; de Haan, J. W.; Smit, B.; Nivarthy, G.; Lercher, J. A.; van Hooff, J. H. C.; van Santen, R. A. J. Phys. Chem. $B$ 1998, 102, 3945 .

(12) van Well, W. J. M.; Cottin, X.; Smit, B.; van Hooff, J. H. C.; van

Santen, R. A. J. Phys. Chem. B 1998, 102, 3952.

(13) Pascual, P.; Boutin, A. Phys. Chem. Chem. Phys. 2004, 6, 2015.

(14) Pascual, P.; Boutin, A.; Ungerer, P.; Tavitian, B.; Fuchs, A. H. Mol. Simul. 2004, 30, 593.

(15) Vaughan, P. A. Acta Crystallogr. 1966, 21, 983.

(16) Fyfe, C. A.; Gies, H.; Kokotailo, G. T.; Marler, B.; Cox, D. E. J. Phys. Chem. 1990, 94, 3718.

(17) Camblor, M. A.; Corma, A.; Díaz-Cabañas, M.-J.; Baerlocher, Ch. J. Phys. Chem. B 1998, 102, 44.

(18) Wagner, P.; Yoshikawa, M.; Lovallo, M.; Tsuji, K.; Taspastis, M.; Davis, M. E. Chem. Commun. 1997, 2179.

(19) Corma, A.; Rey, F.; Rius, J.; Sabater, M. J.; Valencia, S. Nature 2004, 431, 287.

(20) Wagner, P.; Zones, S. I.; Davis, M. E.; Medrud, R. C. Angew. Chem., Int. Ed. 1999, 38, 1269.
(21) Baerlocher, Ch.; Meier, W. M.; Olson, D. H. Atlas of Zeolite Structure Types, 5th ed.; Elsevier Science: Amsterdam, 2001.

(22) Vlugt, T. J. H.; Schenk, M. J. Phys. Chem. B 2002, 106, 12757.

(23) Ryckaert, J. P.; Bellemans, A. Faraday Discuss. Chem. Soc. 1978, $66,95$.

(24) Smit, B.; Siepmann, J. I. J. Phys. Chem. 1994, 98, 8442.

(25) Frenkel, D.; Smit, B. Understanding Molecular Simulations: From Algorithms to Applications, 2nd ed.; Academic Press: San Diego, CA, 2002

(26) Savitz, S.; Siperstein, F.; Gorte, R. J.; Myers, A. L. J. Phys. Chem. B 1998, 102, 6865 .

(27) Eder, F.; Lercher, J. A. J. Phys. Chem. B 1997, 101, 1273.

(28) Ndjaka, J.-M. B.; Zwanenburg, G.; Smit, B.; Schenk, M. Microporous Mesoporous Mater. 2004, 68, 37.

(29) Eder, F.; Lercher, J. A. Zeolites 1997, 18, 75.

(30) Calero, S.; Lobato, M. D.; García-Pérez, E.; Mejías, J. A.; Lago, S.; Vlugt, T. J. H.; Maesen, T. L. M.; Smit, B.; Dubbeldam, D. J. Phys. Chem. B 2006, 110, 5838 .

(31) Karsli, H.; Çulfaz, A.; Yücel, H. Chem. Eng. Commun. 2003, 190, 693.

(32) Long, Y. C.; Ma, M. H.; Sun, Y. J.; Jiang, H. W. J. Inclusion Phenom. Macrocyclic Chem. 2000, 37, 103.

(33) Ma, M. H.; Jiang, H. W.; Long, Y. C.; Sun, Y. J. Acta Chim. Sin. 1998, 56, 405.

(34) García-Pérez, E.; Dubbeldam, D.; Liu, B.; Smit, B.; Calero, S., in preparation.

(35) Du, H. W.; Kalyanaraman, M.; Camblor, M. A.; Olson, D. H. Microporous Mesoporous Mater. 2000, 40, 305.

(36) Guil, J. M.; Guil-López, R.; Perdigón-Melón, J. A.; Corma, A. Microporous Mesoporous Mater. 1998, 22, 269.

(37) Gribov, E. N.; Sastre, G.; Corma, A. J. Phys. Chem. B 2005, 109, 